

Estudos Teológicos foi licenciado com uma Licença Creative Commons Atribuição - NãoComercial - SemDerivados 3.0 Não Adaptada

http://dx.doi.org/10.22351/et.v58i2.3032

\title{
Podem Ser Considerados Protestantes os Batistas? ${ }^{1}$
}

Can the Baptists be considered Protestants?

\section{Valdir Stephanini ${ }^{2}$ Julio Cezar de Paula Brotto ${ }^{3}$}

\begin{abstract}
Resumo: Neste momento em que são comemorados os 500 anos da Reforma Protestante, o presente artigo argumentará sobre a impossibilidade de se comprovar historicamente as origens dos batistas de forma dissociada do pensamento e dos pressupostos da Reforma. Para tanto serão apresentadas as principais teorias sobre as origens dos batistas, a saber: a teoria sucessionista orgânica estrita; a teoria do parentesco anabatista; a teoria do sucessionismo espiritual e a teoria separatista britânica. Apoiado nos argumentos históricos que podem ser verificáveis, o artigo propõe que os batistas, enquanto designados por esse nome distintivo, estão vinculados ao movimento da Reforma em função de importantes doutrinas da Reforma, como a justificação pela fé, a autoridade da Escritura e o sacerdócio universal dos crentes, afirmadas claramente na teologia batista.
\end{abstract}

Palavras-chave: Batistas. Reforma Protestante. Landmarkismo. Eclesiologia.

Abstract: As the 500th anniversary of the Protestant Reformation is celebrated, this article will argue that it is impossible to prove historically the origins of Baptists in a way that is dissociated from the thinking and assumptions of the Reformation. The main theories about the origins of Baptists will be presented, namely: the strict organic successionism theory; the Anabaptist kinship theory; the theory of spiritual sucessionism and the British separatist theory. Based on historical arguments, which may be verifiable, the article proposes that Baptists, as designated by this distinctive name, are bound up with the Reformation movement in light of important doctrines of the Reformation, such as justification by faith, authority of Scripture, and Universal priesthood of believers clearly stated in Baptist theology.

Keywords: Baptists. Protestant Reformation. Landmarkism. Ecclesiology.

1 O artigo foi recebido em 30 de maio de 2017 e aprovado em 20 de abril de 2018 com base nas avaliações dos pareceristas ad hoc.

2 Doutor em Teologia Sistemático-Pastoral pela Pontifícia Universidade Católica do Rio de Janeiro, Rio de Janeiro. Docente do PPGCR da Faculdade Unida de Vitória, ES. Contato: valdir@faculdadeunida.com.br

3 Doutor em Teologia Sistemático-Pastoral pela Pontifícia Universidade Católica do Rio de Janeiro, Rio de Janeiro. Docente do PPGCR da Faculdade Unida de Vitória, ES. Contato: julio.brotto@faculdadeunida.com.br 


\section{Introdução}

Nos últimos séculos, historiadores têm apresentado quatro diferentes teorias explicativas para dar conta da origem dos batistas. Essas teorias são apresentadas neste artigo, não em função de terem o mesmo peso, mas porque fazem parte de um longo debate proveniente do ambiente batista e em certa medida complementam variadas e distintas argumentações.

Nesse sentido o artigo apresentará as principais teorias sobre as origens dos batistas, a saber: a teoria sucessionista orgânica estrita; a teoria do parentesco anabatista; a teoria do sucessionismo espiritual e a teoria separatista britânica. Proporá, por fim, que os batistas, enquanto designados por esse nome distintivo, estão vinculados ao movimento da Reforma Protestante do século 16, sobretudo ao movimento separatista inglês do início do século 17.

Muitos historiadores apresentam a teoria sucessionista orgânica estrita e a teoria do sucessionismo espiritual sob uma mesma ótica, a saber, o sucessionismo, mas as teorias podem e devem ser tratadas separadamente.

\section{Teoria do sucessionismo orgânico estrito}

Uma das teorias mais antigas acerca da origem do movimento batista é conhecida como JJJ, ou seja, Jerusalém, Jordão, João, também chamada de teoria sucessionista orgânica estrita, afirmando que há uma linha ininterrupta de grupos de cristãos batistas desde os tempos em que João Batista efetuava seus batismos no rio Jordão. Essa teoria, que foi rejeitada pelos batistas ingleses, mas aceita pelos batistas americanos do século $19^{4}$, defende que sempre houve igrejas batistas, com outros nomes, no decorrer dos séculos da história do cristianismo. Teoria inicialmente defendida pelo historiador Thomas Crosby ${ }^{5}$, que defendeu a tese de que havia uma relação de parentesco dos batistas com as igrejas do Novo Testamento. Foi muito divulgada no Brasil, sobretudo com a publicação do livro The trail of blood 6 (O Rastro de Sangue), de autoria de um pastor batista americano, J. M. Carrol, publicado em 1931; essa teoria recebeu muitas críticas e manifestações de rejeição.

A teoria de uma linha sucessória ininterrupta de grupos de cristãos batistas desde os tempos do Novo Testamento veio na esteira do landmarkismo, movimento que surgiu na metade do século 19 nos Estados Unidos da América, causando um longo e

4 SILVA, N. T. Do confronto ao diálogo: o estilo batista de ser e a questão ecumênica no Brasil. São Paulo: Fonte, 2012. p. 65.

5 CROSBY, Thomas. The history of the English Baptists, from the Reformation to the beginning of the reign of King George I. London: Tho. Crosby, 1738. v. I.

6 CARROL, J. M. The trail of blood. Following the Cristians down the centuries or the history of Baptist Churches from the time of Christ, their founder, to the present day. Disponível em: <https://archive.org/ stream/TheTrailOfBloodByJimCarroll/The\%20Trail\%20of\%20Blood\%20by\%20Jim\%20Carroll\#page/ n0/mode/2up>. Acesso em: 07 mar. 2018. 
acirrado debate sobre a origem e a identidade batista. Quem são realmente os batistas? Poderiam, em qualquer senso legítimo, ser classificados como protestantes?

A designação landmarkism surgiu de um panfleto escrito por James M. Pendleton, intitulado An Old Landmark Re-Set (Um marco antigo restabelecido), em referência à passagem de Provérbios 22.28, que na língua inglesa utiliza a expressão landmarkism ${ }^{7}$, e foi divulgado a partir de 1856 pelo editor do jornal The Tennessee Baptist, James R. Graves.

O próprio Graves, em 1880, publicou um livro intitulado Old Landmarkism: what is it? (“Antigo Landmarkismo: o que é isto?"), no qual ele explica o surgimento do termo.

O nome "Old Landmakers" surgiu dessa maneira. Em 1854 J. M Pendleton, do Kentucky, escreveu um ensaio sobre esta questão a meu pedido especial, a saber: "Deveriam os Batistas reconhecer os pregadores Pedobatistas como ministros evangélicos?", que publiquei em forma de panfleto e dei o título, "Um marco antigo restabelecido".

Landmarkistas garantem que a igreja batista é anterior à Reforma Protestante e a única realmente neotestamentária. O historiador batista A. R. Crabtree, que advogava essa teoria, afirma:

[...] o povo desta fé é mais antigo do que o seu nome historico, porque é da mesma fé e ordem dos christãos do Novo Testamento. As igrejas apostolicas eram verdadeiramente baptistas porque constavam sómente de crentes baptizados, porque eram democraticas, e porque respeitaram a consciencia e a responsabilidade pessoal. É justamente por esta razão que o Novo Testamento é tão poderoso na criação de igrejas baptistas. [...] um estudo cuidadoso. E ele continua: "um estudo cuidadoso e livre de preconceitos das igrejas apostolicas convencerá qualquer pessoa de que ellas eram essencialmente da mesma fé e ordem das igrejas baptistas de nossos dias?.

Essa proposição será utilizada tanto para consubstanciar a teoria sucessionista orgânica estrita como a teoria do sucessionismo espiritual. Contudo, ambas as teorias carecem de comprovação histórica, ficando apenas no campo das ideias de seus autores.

Mesmo recebendo muitas críticas por parte até mesmo dos próprios batistas, uma vez que não resiste a uma averiguação documental, essa teoria contribuiu muito para a configuração das igrejas batistas filiadas à Convenção Batista Brasileira, espe-

7 THE HOLY BIBLE. King James Version. "Remove not the ancient landmark, which thy fathers have set." Proverbs 22:28. Observe a palavra landmark, que pode ser traduzida por marcos ou limites da terra.

8 GRAVES, J. R. "The origin of the appellation 'Old Landmarkism'. Its present strenght.” In: GRAVES, J. R. Old Landmarkism: what is it? Baptist Book House: Memphis. 1880. p. XII. "The name of Old Landmakers came in this way. In $1854 \mathrm{~J}$. M. Pendleton, of Kentucky, wrote an essay upon this question at my especial request, viz: "Ought Baptists to recognize Pedobaptist preachers as gospel ministers?" which I brought out in tract from, and gave it the title, "An Old Landmark Reset". (tradução nossa).

9 CRABTREE, A. R. Historia dos Baptistas do Brasil-até o anno de 1906. Rio de Janeiro: Casa Publicadora Baptista, 1937. p. 6-7. 
cialmente no que tange à indisposição ao diálogo ecumênico ${ }^{10}$, uma vez que a ideia da sucessão eclesiástica orgânica, a partir das igrejas do Novo Testamento até as igrejas batistas da atualidade, fez com que os batistas se tornassem exclusivistas por muito tempo, entendendo serem eles e somente eles os portadores do genuíno evangelho e da autêntica eclesiologia. ${ }^{11}$ Os batistas pensavam que "eram ao mesmo tempo autônomos em suas igrejas individuais, mas também os únicos autênticos habitantes do reino de Deus e os legítimos descendentes da antiga tradição cristã "12. Na verdade, esse ainda é o pensamento de algumas igrejas batistas, sobretudo aquelas que mantêm uma linha teológico-doutrinária conservadora.

Em função dessa visão exclusivista, advinda do landmarkismo, muitas igrejas batistas filiadas à Convenção Batista Brasileira ainda mantêm "“...] o costume de não compartilhar pão e cálice da Ceia do Senhor com pessoas de outras denominações evangélicas, ou de impor o rebatismo mesmo a quem já foi batizado por imersão em igrejas pertencentes a outras instituições denominacionais"13. Essa visão eclesiológica foi muito divulgada e aceita entre os batistas norte-americanos, que plantaram igrejas batistas em solo brasileiro através do trabalho missionário aqui realizado, sendo motivo de numerosas discussões e cisões de igrejas.

O historiador batista José dos Reis Pereira defende a tese do sucessionismo orgânico estrito ao afirmar que:

[...] os discípulos de Jesus Cristo, que a partir dos Séculos XVII e XVIII passaram a ser conhecidos como Batistas, têm as mesmas doutrinas e práticas das igrejas do $1^{\circ}$ século de nossa era. Mais ainda: as igrejas batistas de hoje podem resistir a uma comparação com as igrejas cristãs do $1^{\circ}$ século. Acrescente-se que, através destes vinte séculos de história do cristianismo, muitos discípulos de Jesus mantiveram essa identificação com o cristianismo neotestamentário. Não tinham o nome de batistas, mas, pela comparação, se pode verificar um estreito parentesco entre eles e os batistas de hoje ${ }^{14}$.

O referido autor influenciou gerações inteiras de pastores batistas com essa teoria, mas não representa o que a maioria dos batistas pensa sobre sua origem. É o que pensa Benilton C. Bezerra quando afirma que "admitir-se a sucessão histórica como essencial para provar a apostolicidade dos batistas é fechar os olhos à própria

${ }^{10}$ Embora não signifique que não existam batistas ou até mesmo igrejas batistas que se mantenham abertas ao diálogo ecumênico, pois cada indivíduo e comunidade batista são livres para viver ecumenicamente a sua fé e sua vida, entretanto o fato é que historicamente a relação dos batistas no Brasil com a questão ecumênica é marcada mais pelo confronto do que pelo diálogo. (Ver considerações importantes sobre esse tema em SILVA, 2012).

${ }^{11}$ GRAVES, J. R. Old Landmarkism: what is it? Baptist Book House: Memphis. 1880. p. 35-42.

${ }^{12}$ AZEVEDO, I. B. A celebração do indivíduo: A formação do pensamento batista brasileiro. Piracicaba: UNIMEP; São Paulo: Exodus, 1996. p. 128.

${ }^{13}$ NOVAES, C. C. P. Vocação para a intolerância. In: PINHEIRO, J.; SANTOS, M. Os batistas: controvérsias e vocação para a intolerância. São Paulo: Fonte, 2012. p. 10.

${ }^{14}$ PEREIRA, J. R. Breve história dos batistas. Rio de Janeiro: Junta de Educação Religiosa e Publicações, 1979. p. 11. 
verdade e forçar meias verdades"15. Assim sendo, fica claro entre os batistas que prezam pelo rigor acadêmico que a teoria do sucessionismo orgânico estrito para explicar a origem das igrejas batistas não resiste ao crivo da pesquisa documental.

\section{Teoria do sucessionismo espiritual}

Identificada como uma variante da anterior, essa teoria pressupõe um sucessionismo espiritual com base nos ensinamentos bíblicos. Há uma continuidade ao longo da história dos conceitos esposados pelos batistas. Afirma que não há um "rastro de sangue", mas há uma perceptível e discernível "trilha da verdade".

O principal proponente dessa teoria é Thomas Armitage, que introduziu uma variante importante na noção do sucessionismo orgânico. No subtítulo de sua obra $A$ history of the Baptists; traced by their vital principles and practices, from the time of our Lord and Saviour Jesus Christ to the year $1886^{16}$ (A história dos Batistas; traçada por seus princípios e práticas vitais, desde o tempo de nosso Senhor e Salvador Jesus Cristo até o ano de 1886) fica clara a intenção dele: traçar uma linha do tempo da noção espiritual.

Nas palavras de Armitage percebe-se que a noção da sucessão espiritual se sobrepõe à teoria da sucessão de perseguição. É possível “[...] seguir certas verdades através dos tempos [...] até os que nos tempos atuais são aqueles que as mantêm, os batistas"17. Ele se posiciona pela impossibilidade de se provar a sucessão dos batistas por meio de uma trilha de sucessão de grupos históricos, visto que a verdadeira linhagem das igrejas apostólicas se encontra em conformidade com o padrão das verdades e ensinos apostólicos. ${ }^{18}$

Outro proponente importante dessa teoria foi Henry Vedder. Embora Henry Vedder tenha procurado rastrear a história batista através dos séculos, ele reconheceu que a história batista alcançou um fundamento sólido apenas no século 17. Ele advogava que

Uma sucessão da fé verdadeira pode ser verdadeiramente traçada, em linhas fracas às vezes, mas nunca desaparecer inteiramente; mas uma sucessão de igrejas, substancialmente como aquelas de nossa própria fé e ordem em doutrina e prática - isto é uma coisa obscura - provavelmente levará o estudante a um lamaçal de erros e a perversão dos fatos ${ }^{19}$.

${ }^{15}$ BEZERRA, B. C. Interpretação panorâmica dos batistas. Rio de Janeiro: Casa Publicadora Batista, 1960. p. 15.

${ }^{16}$ ARMITAGE, Thomas. A history of the Baptists; traced by their vital principles and practices, from the time of our Lord and Saviour Jesus Christ to the year 1886. New York: Bryan; Taylor, 1887.

${ }^{17}$ ARMITAGE, 1887, p. 8, 11.

${ }^{18}$ ARMITAGE, 1887, p. 1.

19 VEDDER, Henry C. A short history of the Baptists. Philadelphia: The American Baptist Publication Society, 1907. p. 9-10. "A succession of the true faith may indeed be traced, in faint lines at times, but never entirely disappearing; but a succession of churches, substantially like those of our own faith and order in doctrine and polity - that is a will-o'-the-wisp, likely to lead the student into a morass of errors, a quagmire of unscholarly perversions of fact." (tradução nossa). 
A questão de fundo da teoria da sucessão espiritual reside na afirmação de que os que interpretam a palavra ekklesia como referência unicamente à igreja local interpretam mal seu uso em passagens onde claramente se refere ao corpo universal de crentes. Existem várias passagens no Novo Testamento onde a palavra ekklesia, ou outras equivalentes, é usada em um sentido universal ou coletivo, ao invés de ter uma noção local. Quando a igreja é designada como corpo de Cristo em passagens como Efésios 1.22-23, 2.16, refere-se à igreja universal. A metáfora do corpo implica unicidade e não multiplicidade de corpos locais. Todas as metáforas utilizadas para designar a noção de igreja sugerem uma igreja universal inclusiva e não uma assembleia local apenas.

Outra posição de cunho espiritual para essa teoria é de que a igreja para ser considerada universal deve se referir a todos os indivíduos redimidos. Para os defensores dessa teoria, nem toda igreja local, embora visível, pode ser necessariamente considerada regenerada. No entanto, o corpo de Cristo - o equivalente à igreja universal - é composto de todos os santos verdadeiros, ao longo do tempo, se visível agora na terra ou invisível no céu.

Além disso, para evidenciar que a teoria do sucessionismo espiritual não tem consistência, Bezerra afirma: "Thomas Helwys, um dos mais altos exemplos de fé batista, já em 1612 ensinava e sofria, em razão do seu ensino, que não há sucessão nas coisas espirituais ${ }^{20}$.

\section{Teoria do parentesco anabatista}

Outra teoria sobre a origem dos batistas, também bastante estimada por alguns, é denominada teoria do parentesco anabatista, que liga as igrejas batistas com o movimento do século 16 conhecido como anabatista, ou rebatizadores, que teria surgido paralelamente ao movimento de reforma da Europa central. Esse grupo teve início em 1525, quando alguns jovens sentindo-se, equivocadamente, incentivados pelo reformador Ulrich Zwínglio ${ }^{21}$, submeteram-se a novo batismo, rejeitando a submissão a qualquer poder eclesiástico, fosse católico ou reformado, defendendo total autonomia das comunidades cristãs em relação a qualquer hierarquia religiosa ou política.

Formado especialmente por camponeses que visualizavam na Reforma os elementos necessários para a transformação da sociedade e da igreja, esse movimento levou seus adeptos a examinar mais criticamente a ordem social estabelecida e a buscar uma mudança mais radical de $\operatorname{ambos}^{22}$, recebendo por isso o nome de Reforma Radical. Em função dessa radicalização de seus posicionamentos frente aos princípios norteadores da Reforma, o grupo sofreu forte oposição e perseguição, tanto por parte dos reformadores como da Igreja Católica.

${ }^{20}$ BEZERRA, 1960, p. 15.

${ }^{21}$ Para Zwínglio, o sacramento era sinal da realidade já ocorrida e não produtor dessa realidade; perdia necessidade o batismo de crianças e podia-se utilizar o batismo como sinal público.

22 SILVA, 2012, p. 65-66. 
Alinhados com esse tipo de reforma estão os anabatistas, tendo Thomas Müntzer como um dos seus líderes. Müntzer preconizou uma reforma sociorreligiosa, entendendo que igreja é "uma comunidade sem classes e sem a existência de propriedade privada, dos 'eleitos', através da posse do Espírito. Em outras palavras: igreja é um ideal social, onde inexistem Estado, classes, propriedade privada" ${ }^{23}$. Como consequência dessa reforma pregada por Müntzer e seus seguidores, seus bens foram confiscados, sendo também banidos e martirizados. Apesar dos excessos cometidos por esse movimento, teria sido muito positiva essa visão de busca da transformação da sociedade, o que não se vê na ênfase nem na configuração da maioria das igrejas batistas da Convenção Batista Brasileira. ${ }^{24}$

Essa teoria foi defendida por historiadores pelo iniciador do movimento conhecido nos Estados Unidos como Evangelho Social, o pastor e professor Walter Rauschenbusch ${ }^{25}$, mas não conta com a simpatia da maioria dos teólogos e lideranças batistas brasileiros. Acredita-se, entretanto, que os batistas são descendentes espirituais do movimento anabatista ${ }^{26}$, tendo sido por ele influenciados, mas não se vê continuidade histórica entre os dois grupos. ${ }^{27}$ Embora isso seja relevante, é bom que se diga que outros grupos também foram influenciados pelo movimento anabatista, sobretudo no que diz respeito à separação igreja e estado, batismo após a profissão de fé espontânea do crente, liberdade religiosa irrestrita e competência da alma. ${ }^{28}$ Isso não significa que esses grupos tenham ligação histórica com os anabatistas, mas que por eles foram influenciados, a exemplo do que aconteceu com os batistas. Entretanto, os batistas não se identificam com os anabatistas na aversão destes pelos juramentos e pelos cargos públicos, tampouco adotam o pacifismo extremado, a doutrina do sono da alma e a necessidade de sucessão apostólica para a ministração do batismo. ${ }^{29}$ Como se vê, embora haja uma influência do movimento anabatista no surgimento das igrejas batistas, não é possível identificar os batistas como herdeiros do movimento anabatista.

\section{Teoria separatista britânica}

A teoria separatista britânica é outra maneira de interpretar a história dos batistas. Como o próprio nome sugere, essa teoria "afirma que os batistas se originaram

${ }^{23}$ DREHER, M. História do povo de Jesus: uma leitura latino-americana. São Leopoldo: Sinodal, 2013. p. 280.

${ }^{24}$ A Convenção Batista Brasileira (CBB) é o órgão máximo da denominação batista no Brasil. É a maior convenção batista da América Latina, representando cerca de sete mil igrejas, quatro mil missões e 1.350.000 fiéis. Como instituição, existe desde 1907, servindo às igrejas batistas brasileiras como sua estrutura de integração e seu espaço de identidade, comunhão e cooperação. É ela que define o padrão doutrinário e unifica o esforço cooperativo dos batistas do Brasil. Disponível em: < http://www.convencaobatista.com.br/ siteNovo/pagina.php?MEN_ID=19>. Acesso em: 07 mar. 2018.

25 PEREIRA, 1979, p. 10.

${ }^{26}$ PEREIRA, 1979, p. 9.

27 PINHEIRO, J.; SANTOS, M. Os batistas: controvérsias e vocação para a intolerância. São Paulo: Fonte, 2012. p. 18 .

28 PINHEIRO; SANTOS, 2012, p. 19.

29 PEREIRA, J. R. Breve história dos batistas. Rio de Janeiro: Casa Publicadora Batista, 1979. p. 10. 
dos separatistas ingleses, especialmente aqueles que eram congregacionais na eclesiologia e insistiam na necessidade do batismo somente de regenerados"30. Essa é a teoria mais aceita pelos batistas atualmente, defendida pelos norte-americanos, entre eles, o teólogo Augustus Hopkins Strong e o historiador Henry C. Vedder. A teoria que afirma que "depois de 1610 temos uma sucessão ininterrupta de igrejas batistas, estabelecidas com provas documentais indubitáveis" ${ }^{\prime 3}$. Bezerra, por sua vez, afirma que "os historiadores modernos são unânimes em reconhecer que os batistas surgiram na

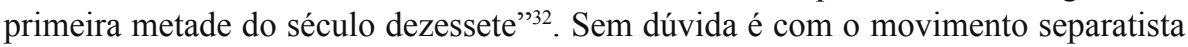
inglês que as igrejas batistas brasileiras melhor se identificam, sobretudo no que tange aos princípios básicos defendidos e a configuração das igrejas locais. ${ }^{33}$

Conquanto os batistas se orgulham de não ter nenhum líder fundador além de Jesus Cristo, dois nomes estão diretamente ligados ao surgimento do movimento batista: o pastor John Smyth, que nasceu em 1568, na Inglaterra, estudou na Universidade de Cambridge e em 1594 foi consagrado ao sacerdócio e nomeado professor na Igreja Anglicana. Em 1598, deixou o ministério oficial da Igreja Anglicana por se casar. Em 1606, aliou-se a uma congregação separatista e logo foi escolhido como seu pastor. Eram tempos difíceis na Inglaterra. Havia muita perseguição para quem pensasse de maneira divergente da igreja oficial, que era a Igreja Anglicana. Em 1608, o grupo de crentes liderado pelo Pr. John Smyth, que se entendia como "povo livre do Senhor"34, imigrou, inteiro, para a Holanda, a fim de escapar das perseguições do governo inglês, estabelecendo-se em Amsterdã. Em 1609, o Pr. John Smyth, influenciado pelos menonitas ${ }^{35}$, batizou-se a si mesmo ${ }^{36}$ e depois batizou os outros 40 membros da congregação. Fez isso inspirado no ensino bíblico, registrado em Marcos 16.16, que diz: "Quem crer e for batizado será salvo". Deu-se origem a uma igreja com todas as características de uma igreja batista. Smyth morreu pouco tempo depois, ainda na Holanda. ${ }^{37}$

Outro nome que se destaca na gênese do movimento batista é do advogado Thomas Helwys. Era em sua casa, na Inglaterra, que se reunia a congregação de separatistas antes de se mudarem para a Holanda. Foi ele quem forneceu os recursos financeiros suficientes para que o grupo todo se mudasse para a Holanda. Em 1611, depois da morte de Smyth, retornou para a Inglaterra, liderando um grupo de dez pessoas. Localizaram-se

${ }^{30}$ PEREIRA, 1979, p. 10.

${ }^{31}$ PEREIRA, 1979, p. 10.

32 BEZERRA, 1960, p. 14.

${ }^{33}$ BEZERRA, 1960, p. 20. Bezerra, citando Robert G. Torbet, que em sua obra A History of the Baptists faz menção de seis princípios fundamentais dos batistas: as Sagradas Escrituras como única norma de fé e prática, a igreja neotestamentária composta de crentes convertidos e batizados por imersão, o sacerdócio universal dos crentes, a autonomia das congregações locais, a liberdade religiosa e a separação de igreja e estado.

${ }^{34}$ AZEVEDO, 1996, p. 77.

${ }^{35}$ CAIRNS, E. E. O cristianismo através dos séculos: uma história da igreja cristã. São Paulo: Vida Nova, 2008. p. 306.

${ }^{36}$ AZEVEDO, 1996, p. 77.

${ }^{37}$ PEREIRA, 1979, p. 68. 
nos arredores de Londres, num lugarejo chamado de Stapfields. Lá, em 1612, organizaram uma igreja com as mesmas características daquela deixada na Holanda. Helwys foi preso por ter escrito um livro ${ }^{38}$ em que defendia um dos princípios básicos dos batistas: a liberdade religiosa. Ele acabou morrendo na prisão em 1615. ${ }^{39}$

A igreja de Stapfields e as que dela se originaram passaram a ser chamadas de Igrejas Batistas Gerais, pois admitiam a redenção geral das pessoas mediante a fé e não aceitavam a doutrina da predestinação desposada por Calvino. Entre 1633 e 1638, surgiu outro grupo de batistas na Inglaterra, que defendia a doutrina da predestinação. Em função disso, esses batistas eram denominados de Batistas Particulares. Há informações de que até o ano de $1642^{40}$, o batismo praticado pelas igrejas batistas era por aspersão. A partir dessa data, entretanto, compreendendo melhor a doutrina bíblica sobre o batismo, os batistas passaram a batizar os crentes por imersão. Só a partir de 1654 é que o nome "batista" foi utilizado pública e oficialmente.

Apesar de defender a autonomia da igreja local ${ }^{41}$ desde os seus primórdios, os batistas aprenderam a cooperar uns com os outros. Em 1644, sete igrejas batistas se reuniram em Londres para publicar uma declaração doutrinária (confissão de fé). Daí em diante, as igrejas batistas fizeram causa comum e formaram associações. Essas associações marcam o início da denominação batista. Três motivos levaram as igrejas a se organizarem em associações e, mais tarde, convenções: a necessidade de relações fraternas com outras igrejas da mesma fé e ordem, necessidade de consulta sobre questões doutrinário-disciplinares e somatória de forças para a realização da obra de

38 O livro escrito por Thomas Helwys se intitulava "Uma Breve Declaração sobre o Mistério da Iniquidade", reivindicando liberdade de consciência para todos/as ao afirmar: "[...] a religião do homem está entre Deus e ele: o rei não tem que responder por ela e nem pode o rei ser juiz entre Deus e o homem. Que haja, pois, heréticos, turcos ou judeus ou outros mais, não cabe ao poder terreno puni-los de maneira nenhuma”. Cf. PEREIRA, 1979 , p. 69.

39 PEREIRA, 1979, p. 69.

40 AZEVEDO, 1996, p. 79.

${ }^{41}$ Eis o que a Declaração Doutrinária da Convenção Batista Brasileira afirma sobre igreja: "Igreja é uma congregação local de pessoas regeneradas e batizadas após profissão de fé. É nesse sentido que a palavra 'igreja' é empregada no maior número de vezes nos livros do Novo Testamento (Mt 18.17; At 5.11; 20.17-28; 1Co 4.17). Tais congregações são constituídas por livre vontade dessas pessoas com finalidade de prestarem culto a Deus, observarem as ordenanças de Jesus, meditarem nos ensinamentos da Bíblia para a edificação mútua e para a propagação do evangelho (At 2.41,42). As igrejas neotestamentárias são autônomas, têm governo democrático, praticam a disciplina e se regem em todas as questões espirituais e doutrinárias exclusivamente pelas palavras de Deus, sob a orientação do Espírito Santo (Mt 18.15-17.3). Há nas igrejas, segundo as Escrituras, duas espécies de oficiais: pastores e diáconos. As igrejas devem relacionar-se com as demais igrejas da mesma fé e ordem e cooperar, voluntariamente, nas atividades do reino de Deus. O relacionamento com outras entidades, quer seja de natureza eclesiástica ou outra, não deve envolver a violação da consciência ou o comprometimento da lealdade a Cristo e sua palavra. Cada igreja é um templo do Espírito Santo (At 20.17,28; Tt 1.5-9; 1Tm 3.1-13.4). Há também no Novo Testamento um outro sentido da palavra igreja, em que ela aparece como a reunião universal dos remidos de todos os tempos, estabelecida por Jesus Cristo e sobre ele edificada, constituindo-se no corpo espiritual do Senhor, do qual ele mesmo é a cabeça. Sua unidade é de natureza espiritual e se expressa pelo amor fraternal, pela harmonia e cooperação voluntária na realização dos propósitos comuns do reino de Deus (Mt 16.18; Cl 1.18; Hb 12.22-24; Ef 1.22,23.5)”. Disponível em: <http://www.convencaobatista.com.br/ siteNovo/pagina.php?MEN_ID=22>. Acesso em: 07 mar. 2018. 
Deus. Seguindo essa filosofia, em 1660, foi organizada a assembleia geral de todas as associações batistas da Inglaterra. Nascia definitivamente a denominação batista. Segundo John Landers, "os batistas surgiram por causa de seu consenso doutrinário sobre a natureza da salvação, da igreja e das ordenanças" ${ }^{2}$. A doutrina uniu os primeiros batistas, mas esses irmãos também tinham diferenças entre si. Eles se uniram na base de seus pontos comuns. Mesmo diante dos pontos comuns em relação a questões doutrinárias, os batistas sempre se mantiveram abertos no que tange à configuração das igrejas locais, bem como à liturgia, podendo essa ser aplicada de acordo com o contexto onde as comunidades locais estivessem localizadas.

Fugindo da perseguição religiosa na Inglaterra, alguns colonos ingleses imigraram para a América do Norte. Entre esses colonos estava Roger Williams, homem de grande influência política na época da colonização americana, que também comandou a organização em Providence, em 1639, da Primeira Igreja Batista naquele país. ${ }^{43}$ Nos Estados Unidos da América, houve um rápido crescimento do trabalho batista, com a multiplicação de igrejas e a organização da denominação.

Dos Estados Unidos os batistas se espalharam para várias partes do mundo, chegando inclusive ao Brasil. Depois de algumas tentativas frustradas, no dia 10 de setembro de 1871 foi organizada, na cidade de Santa Bárbara do Oeste, no estado de São Paulo, numa colônia de imigrantes americanos, a Primeira Igreja Batista em solo brasileiro. ${ }^{44}$ De São Paulo os batistas se espalharam pelo Brasil afora, chegando ao estado do Espírito Santo, onde, no dia 21 de agosto de 1903, na localidade de Ribeirão do Firme, município de Afonso Cláudio, foi organizada a Primeira Igreja Batista em solo capixaba. ${ }^{45}$

Os batistas definem sua identidade à luz de princípios e doutrinas que lhes são comuns. Embora não haja um consenso de quais são os princípios básicos do movimento batista, Silva ${ }^{46}$ lista oito que estão presentes em toda a história do movimento: $1^{\circ}$ princípio do senhorio de Jesus Cristo sobre tudo e sobre todos; $2^{\circ}$ autoridade da Bíblia como única regra de fé e prática; $3^{\circ}$ igreja composta de membros regenerados e biblicamente batizados que a ela se unem voluntariamente; $4^{\circ}$ igreja como comunidade local, democrática e autônoma; $5^{\circ}$ separação entre igreja e estado; $6^{\circ}$ liberdade religiosa e de consciência; $7^{\circ}$ competência do indivíduo e sua responsabilidade diante de Deus; $8^{\circ}$ missão da igreja no mundo. Landers, por sua vez, acrescenta mais sete princípios: $1^{\circ} \mathrm{o}$ livre exame e a livre interpretação das Escrituras; $2^{\circ}$ salvação pela graça; $3^{\circ}$ o Espírito Santo em cada crente a partir de sua conversão a Jesus Cristo; $4^{\circ} \mathrm{o}$ ministério cristão composto por servos dos servos de Deus; $5^{\circ}$ as ordenanças (batismo

${ }^{42}$ LANDERS, J. Teologia dos princípios batistas. Rio de Janeiro: Junta de Educação Religiosa e Publicações, 1986. p. 55.

${ }_{43}$ PINHEIRO; SANTOS, 2012, p. 27.

${ }^{44}$ PINHEIRO; SANTOS, 2012, p. 33.

${ }^{45}$ FARIAS, M. Pelos caminhos anunciai. Vitória: Convenção Batista do Estado do Espírito Santo, 1991. p. 20.

${ }^{46}$ SILVA, R. A. Princípios e doutrinas batistas: os marcos de nossa fé. Rio de Janeiro: JUERP, 2003. p. 27. 
e ceia) como símbolos da salvação; $6^{\circ}$ cooperação entre igrejas batistas; $7^{\circ}$ restrições quanto ao movimento ecumênico. ${ }^{47}$

Em termos doutrinários, os batistas afirmam ter a Bíblia, as Escrituras Sagradas, como única regra de fé e prática e que cada indivíduo tem o direito de examiná-las e interpretá-las. Entretanto, ao longo de sua história, as igrejas batistas foram elaborando documentos contendo conjuntos de doutrinas denominadas confissões de fé. No início do movimento, cada congregação tinha sua própria confissão de fé. À medida que a obra se espalhava pela Europa e América do Norte, sentiu-se a necessidade de elaborar algo que expressasse os pontos comuns a todas as igrejas batistas. Foi assim que surgiram as confissões de fé regionais. Entre as principais confissões de fé batistas, destacam-se: Primeira Confissão de Londres (1644 - Inglaterra), Segunda Confissão de Londres (1689 - Inglaterra), Confissão de Fé de New Hampshire (1833 Estados Unidos) e a Declaração de Mensagem e Fé Batistas (1925 - Estados Unidos).

Segundo Azevedo ${ }^{48}$, os batistas no Brasil utilizaram por muito tempo a tradução da declaração de fé New Hampshire ${ }^{49}$, feita por Z. C. Taylor e que foi oficializada nos anos 1930.

Em 1983, a Assembleia Anual da Convenção Batista Brasileira, ocasião em que celebrava o centenário dos batistas no Brasil, votou a nomeação de uma comissão para elaborar uma declaração de fé por batistas brasileiros. Em sua Assembleia Anual em 1985, aprovaram a nova declaração de fé, a primeira e única elaborada por brasileiros, que recebeu o nome de Declaração Doutrinária da Convenção Batista Brasileira, com 19 de suas principais doutrinas apresentadas nesta ordem: I. Escrituras Sagradas; II. Deus; III. O Homem; IV. O Pecado; V. Salvação; VI. Eleição; VII. Reino de Deus; VIII. Igreja; IX. O Batismo e a Ceia do Senhor; X. O Dia do Senhor; XI. Ministério da Palavra; XII. Mordomia; XIII. Evangelização e Missões; XIV. Educação Religiosa; XV. Liberdade Religiosa; XVI. Ordem Social; XVII. Família; XVIII. Morte; XIX. Justos e Ímpios ${ }^{50}$. Atualmente o parâmetro para medir a identidade das igrejas batistas, que as possibilite a fazer parte da Convenção Batista Brasileira é essa declaração doutrinária.

47 LANDERS, 1986, p. 9.

48 AZEVEDO, 1996, p. 207.

49 A Confissão de Fé de New Hampshire foi redigida pelo Rev. John Newton Brown (1803-1868), no estado de New Hampshire, por volta de 1833, e publicada por uma comissão da Convenção Batista daquele estado. Ela foi adotada pela mesma convenção, chegando a influenciar outras confissões, sendo uma das mais largamente aceitas e amplamente usadas confissões de fé batista nos Estados Unidos, especialmente nos estados do norte e do oeste. Trata-se de uma confissão clara e concisa da fé denominada batista, em harmonia com as doutrinas de confissões mais antigas, porém expressa em forma mais moderada. Ela é relativamente breve quando comparada com outras confissões, contendo 18 artigos. De um modo geral, sua tendência é calvinista moderada e relembra a fé dos protestantes ortodoxos. Com a chegada dos missionários americanos no final do século 19 ao Brasil, a Confissão de Fé de New Hampshire tornou-se a declaração dos batistas brasileiros, passando a ser conhecida como "Declaração de Fé das Igrejas Batistas do Brasil”. Cf. PEREIRA, Francisco Bonato. PIB da Bahia (1882): a expansão do cristianismo Batista no Brasil. O Jornal Batista, Rio de Janeiro, a. CXV, ed. 43, domingo, 2 out. 2016, p. 06.

${ }^{50}$ CONVENÇÃO BATISTA BRASILEIRA. Declaração Doutrinária. Disponível em: $<$ http://www.convencaobatista.com.br/siteNovo/pagina.php?MEN_ID=22>. Acesso em: 07 mar. 2018. 


\section{Considerações finais}

O foco do artigo estava em apresentar um argumento acerca da indagação sobre as origens dos batistas e se os mesmos podem ser identificados como protestantes. Se alguém toma um atalho, ou opta por uma explicação historicamente detalhada, a única resposta possível é que os batistas têm sua origem histórica no movimento reformador.

É importante notar que os defensores de todas as teorias afirmam a autoridade do Novo Testamento para amparar suas posições. Duas teorias são similares na medida em que afirmam um sucessionismo linear das igrejas e das doutrinas batistas a partir uma visão orgânica estrita proveniente de grupos históricos que interpretaram a fé de forma semelhante, ou por meio de um sucessionismo de cunho espiritual com base na interpretação do Novo Testamento considerando a doutrina apostólica preservada e observável ao longo dos séculos. Para ambos os grupos é preciso identificar algum tipo de conexão orgânica para os batistas terem legitimidade.

As outras duas teorias tomam por base a historicidade da igreja a partir do parentesco anabatista e dos separatistas britânicos. Assumem que a igreja é universal e local. Com base nessa premissa, juntamente com fatos extraídos de outras evidências históricas já identificadas, pode-se demonstrar que os batistas, em alguma medida, pertenceram ao movimento protestante do século 16.

Importantes doutrinas da Reforma como a justificação pela fé, a autoridade da Escritura e o sacerdócio universal dos crentes são afirmadas claramente na teologia batista. ${ }^{51}$ Além disso, os fatos históricos indicam que os batistas se originaram do separatismo inglês, certamente uma parte do movimento protestante do século 16 . Ainda que fosse o caso de se assumir a influência anabatista, seria necessário admitir que os próprios anabatistas surgiram como fruto do movimento reformador.

A tendência de negar que os batistas são protestantes cresce a partir de uma visão defeituosa da história, a saber, que as igrejas batistas têm existido em cada século e com nomes diferentes e, portanto, antecedem ao movimento da Reforma. O próprio nome batista não foi utilizado pelos primeiros grupos desde o seu surgimento. Seus adversários muitas vezes os chamavam de "anabatistas". Eles, porém, preferiam se designar como "irmãos", "igrejas batizadoras" e "Igrejas do caminho batizado". No início da década de 1640, alguns oponentes os chamavam de "batistas". O grupo passou a usar o nome batista em meados da década de 1650, mas levou um século inteiro para ser aceito de forma ampla.

Por conveniência, as "igrejas batizadoras" passaram a ser identificadas como "batistas". É preciso compreender que não apenas a designação batista é assumida com o passar dos anos, mas também afirmar que a maioria dessas igrejas continuou por um tempo em uma condição extremamente fluida, em busca de uma identidade própria, por assim dizer. Algumas dessas igrejas, eventualmente, fizeram a adesão nas estruturas batistas emergentes, como associações e conferências dos ministros,

${ }^{51}$ AZEVEDO, 1996, p. 88. 
enquanto outras não. A denominação batista, no sentido moderno dessa palavra, emergiu gradualmente ao longo de um extenso período de tempo, tendo certamente suas origens históricas atreladas ao movimento protestante como um todo.

\section{Referências}

ARMITAGE, Thomas. A history of the Baptists; traced by their vital principles and practices, from the time of our Lord and Saviour Jesus Christ to the year 1886. New York: Bryan; Taylor, 1887. AZEVEDO, I. B. A celebração do indivíduo: A formação do pensamento batista brasileiro. Piracicaba: UNIMEP; São Paulo: Exodus, 1996.

BEZERRA, B. C. Interpretação panorâmica dos batistas. Rio de Janeiro: Casa Publicadora Batista, 1960.

CAIRNS, E. E. O cristianismo através dos séculos: uma história da igreja cristã. São Paulo: Vida Nova, 2008.

CARROL, J. M. The trail of blood. Following the Christians down the centuries or the history of Baptist Churches from the time of Christ, their founder, to the present day. Disponivel em: $<$ https://archive.org/stream/TheTrailOfBloodByJimCarroll/The\%20Trail\%20of\%20Blood\%20 by\%20Jim\%20Carroll\#page/n0/mode/2up>. Acesso em: 07 mar. 2018.

CRABTREE, A. R. Historia dos Baptistas do Brasil - até o ano de 1906. Rio de Janeiro: Casa Publicadora Baptista, 1937.

CROSBY, Thomas. The history of the English Baptists, from the Reformation to the beginning of the reign of King George I. London: Tho. Crosby, 1738. v. I.

DREHER, M. História do povo de Jesus: uma leitura latino-americana. São Leopoldo: Sinodal, 2013. FARIAS, M. Pelos caminhos anunciai. Vitória: Convenção Batista do Estado do Espírito Santo, 1991. GRAVES, J. R. Old Landmarkism: what is it? Baptist Book House: Memphis, 1880.

LANDERS, J. Teologia dos princípios batistas. Rio de Janeiro: Junta de Educação Religiosa e Publicações, 1986.

NOVAES, C. C. P. Vocação para a intolerância. In: PINHEIRO, J.; SANTOS, M. Os batistas: controvérsias e vocação para a intolerância. São Paulo: Fonte, 2012. p. 9-12.

PEREIRA, Francisco Bonato. PIB da Bahia (1882): A expansão do cristianismo Batista no Brasil. O Jornal Batista, Rio de Janeiro, a. CXV, ed. 43, domingo, 23 out. 2016.

PEREIRA, J. R. Breve história dos batistas. Rio de Janeiro: Casa Publicadora Batista, 1979.

PINHEIRO, J.; SANTOS, M. Os batistas: controvérsias e vocação para a intolerância. São Paulo: Fonte, 2012.

SILVA, N. T. Do confronto ao Diálogo: o estilo batista de ser e a questão ecumênica no Brasil. São Paulo: Fonte, 2012.

SILVA, R. A. Princípios e doutrinas batistas: os marcos de nossa fé. Rio de Janeiro: JUERP, 2003. VEDDER, Henry C. A short history of the Baptists. Philadelphia: The American Baptist Publication Society, 1907. 